\title{
вмJ Global Health Who is telling the story? A systematic review of authorship for infectious disease research conducted in Africa, 1980-2016
}

\author{
Rose Mbaye, ${ }^{1}$ Redeat Gebeyehu, ${ }^{2}$ Stefanie Hossmann, ${ }^{3}$ Nicole Mbarga, ${ }^{4,5}$ \\ Estella Bih-Neh, ${ }^{6}$ Lucrece Eteki, ${ }^{7}$ Ohene-Agyei Thelma, ${ }^{8}$ Abiodun Oyerinde, ${ }^{9}$ \\ Gift Kiti, ${ }^{10}$ Yvonne Mburu, ${ }^{11}$ Jessica Haberer, ${ }^{12,13}$ Mark Siedner, ${ }^{14}$ Iruka Okeke, ${ }^{9}$ \\ Yap Boum (1D) 7,15
}

\begin{abstract}
To cite: Mbaye R, Gebeyehu R, Hossmann $\mathrm{S}$, et al. Who is telling the story? A systematic review of authorship for infectious disease research conducted in Africa, 19802016. BMJ Global Health 2019;4:e001855. doi:10.1136/ bmjgh-2019-001855
\end{abstract}

Handling editor Seye Abimbola

Received 19 July 2019

Revised 23 September 2019 Accepted 28 September 2019

Check for updates

(c) Author(s) (or their employer(s)) 2019. Re-use permitted under CC BY-NC. No commercial re-use. See rights and permissions. Published by BMJ.

For numbered affiliations see end of article.

Correspondence to Professor Yap Boum; yap.boum@epicentre.msf.org

\section{ABSTRACT}

Introduction Africa contributes little to the biomedical literature despite its high burden of infectious diseases. Global health research partnerships aimed at addressing Africa-endemic disease may be polarised. Therefore, we assessed the contribution of researchers in Africa to research on six infectious diseases.

Methods We reviewed publications on HIV and malaria (2013-2016), tuberculosis (2014-2016), salmonellosis, Ebola haemorrhagic fever and Buruli ulcer disease (19802016) conducted in Africa and indexed in the PubMed database using Preferred Reporting Items for Systematic Reviews and Meta-Analyses protocol. Papers reporting original research done in Africa with at least one laboratory test performed on biological samples were included. We studied African author proportion and placement per study type, disease, funding, study country and lingua franca.

Results We included 1182 of 2871 retrieved articles that met the inclusion criteria. Of these, 1109 (93.2\%) had at least one Africa-based author, 552 (49.8\%) had an African first author and $41.3 \%(n=458)$ an African last author. Papers on salmonellosis and tuberculosis had a higher proportion of African last authors $(p<0.001)$ compared with the other diseases. Most of African first and last authors had an affiliation from an Anglophone country. HIV, malaria, tuberculosis and Ebola had the most extramurally funded studies ( $\geq 70 \%$ ), but less than $10 \%$ of the acknowledged funding was from an African funder.

Conclusion African researchers are under-represented in first and last authorship positions in papers published from research done in Africa. This calls for greater investment in capacity building and equitable research partnerships at every level of the global health community.

\section{INTRODUCTION}

Africa faces a high burden from infectious diseases with, for example, $90 \%$ of all HIV and malaria deaths in children in developing countries occurring South of the Sahara. Ebola and Buruli ulcer are neglected and

\section{Key questions}

What is already known?

- Africa fares very poorly regarding publications in research and innovation, where international collaboration for research conducted in Africa tends to under-represent African researchers yet secures key authorship for non-African researchers.

What are the new findings?

- Our study suggests that despite their significant contribution, African authors are highly under-represented as first and last authors in collaborative infectious disease research conducted within the African continent.

- Most of African first and last authors had affiliations in Anglophone countries.

What do the new findings imply?

- This calls for capacity building and equitable partnership between African countries and western nations for scientific research and publication.

- There is a need for more efforts to include Frenchspeaking African researchers in research collaborations and a need for an active valorisation of research studies published in French-written journals.

under-researched diseases whereby progress towards preventive measures for them has been slow. ${ }^{2}$ The devastating effects of these infectious diseases and their potential to spread drive an international imperative to address them through research. Mutually beneficial partnerships between African countries and Western nations for scientific research and publication have the potential to improve research capacity and address global health challenges. Research in endemic areas also provides training and career development opportunities for both African and Western scientists. 
In the past decades, international researchers are increasingly conducting clinical trials in low-income and middle-income countries (LMICs). ${ }^{1}$ Authors from the USA and Western Europe make up a striking $80 \%$ of the articles published in infectious diseases journals worldwide. ${ }^{3}$ On the other hand, most low-income regions are tremendously under-represented in the research literature. The African continent produces only about $1 \%$ of the world's research publications and $0.1 \%$ of global patents, and the bulk of publications emanate from just three countries. ${ }^{4}$ South Africa accounts for one-third of Africa's publication output, while Egypt and Nigeria jointly account for another one-third. ${ }^{56}$

African researchers commonly publish internationally in collaboration with Western scientists. Consequently, there has been a gradual increase in the volume of scientific publications from and about Africa, with a noticeable dominance by non-African coauthors. ${ }^{78}$ However, inequity in research partnerships can hinder true progress. ${ }^{9}$ For instance, collaborations across countries might create authorship disputes as a result of false expectations, unclear arrangements and poor communication between those concerned. ${ }^{10}$ Traditionally, at least in the biomedical sciences, the last author is usually an eminent professor or senior in the research field who is credited for leading the research, while the first author is usually the one who bears the highest day-to-day research workload for the project. Either the first or the last author coordinates the collaborative team and correspond with the journal through peer review. ${ }^{11} 12$

High-income country researchers control funding and therefore can dictate research agendas in Africa. ${ }^{13}$ Accordingly, African authors could be under-represented in writing up collaborative work for publication and this is especially true for authorship positions of first or last authors which are sometimes driven by competition for resources and the desire for recognition. ${ }^{11}$ It is not clear to what extent imbalances in global health partnerships affect African authorship and positions in infectious disease research. To achieve success in global health research partnerships, it is an imperative to gain an understanding of the extent of the problem and address any concerns in authorship trends. This paper assesses authorship positions and the proportion of African researchers in medical research conducted in Africa. We also aim to compare proportions of lead and last authorship by study type, disease, study country and lingua franca of Africa-based lead and last authors.

\section{METHODS}

We performed a systematic review of the primary biomedical literature indexed in Medline (PubMed) ${ }^{14}$ Relevant elements of the Preferred Reporting Items for Systematic Reviews and Meta-Analyses guidelines were followed in conducting and reporting the findings of this review. ${ }^{15} \mathrm{Six}$ diseases were selected as case studies for the assessment. We chose Africa-endemic diseases (Ebola haemorrhagic fever, malaria, Buruli ulcer); diseases that occur predominantly but not exclusively in low-income settings (salmonellosis) as well as infectious conditions of international concern that exert a predominant burden in Africa (HIV, tuberculosis). ${ }^{16-18}$ Our six case studies include diseases caused by viruses, bacteria and parasite, as well as easy and difficult to culture organisms. We also selected diseases for which there was a sufficient body of literature to provide power to analyses and diseases in which at least one member of our team had research expertise.

We performed independent searches for clinical trials and epidemiological studies done in Africa on each of the six selected diseases, that is, HIV, malaria, tuberculosis, salmonellosis, Ebola and Buruli ulcer. Of the six diseases, three are moderately researched in Africa, based on their hits on PubMed between 1980 and 2016. The other three were highly researched infectious diseases (HIV, malaria and tuberculosis). These yielded a higher number of hits in the same period-5716, 3421 and 1685, respectively-and hence were researched for shorter periods for the purpose of this study. Thus, among clinical trials and epidemiological studies done in Africa, all papers on tuberculosis published between 1 August 2013 and 31 July 2016 and all papers on malaria and HIV, published between 1 August 2014 and 31 July 2016, were extracted from PubMed. In addition, all clinical trials and epidemiological studies done in Africa on salmonellosis, Buruli ulcer and Ebola, published between 1 August 1980 and 31 July 2016, were extracted from PubMed.

Separate searches were performed to retrieve papers reporting clinical trials and epidemiological findings for all six diseases. Specific key search terms were systematically used using all the different possible combinations between the types of studies (clinical and epidemiological), the different diseases (HIV, malaria, tuberculosis, salmonellosis, Ebola and Buruli) and all the 54 African countries in addition to the word Africa. A sample of one possible combination considering the types of study as 'epidemiological', 'Ebola' as the chosen disease and the 'list of African countries' would look like:

I. 'Epidemiology OR Epidemiological' AND
Laboratory
II. 'Ebola' AND
III. Africa OR Algeria OR Angola OR Benin OR Botswana OR Burkina Faso OR Burundi OR Cameroon OR Cape Verde OR Central African Republic OR Chad OR Comoros OR Congo OR Cote d'Ivoire OR Democratic Republic of the Congo OR Djibouti OR Equatorial Guinea OR Eritrea OR Ethiopia OR Egypt OR Gabon OR Gambia OR Ghana OR Guinea OR Guinea-Bissau OR Kenya OR Lesotho OR Liberia OR Libya OR Madagascar OR Malawi OR Mali OR Morocco OR Mauritius OR Mauritania OR Mozambique OR Namibia OR Niger OR Nigeria OR Rwanda OR Soa Tome and Principe OR Senegal OR Seychelles OR Sierra Leone OR Somalia OR South Africa OR Sudan OR South Sudan OR Swaziland OR 


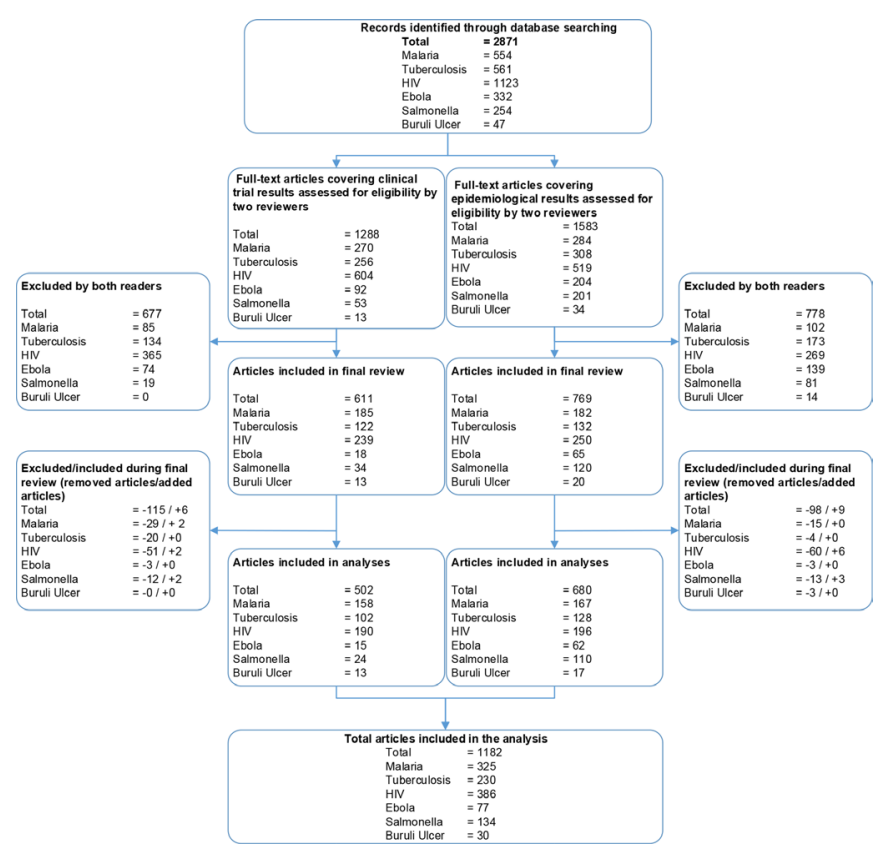

Figure 1 Flow chart of study selection.

Three moderately researched diseases in Africa

(salmonellosis, Ebola and Buruli; 1980-2016) and three highly researched diseases in Africa (tuberculosis, 2013-2016; and HIV and malaria, 2014-2016).

Togo OR Tunisia OR Uganda OR United Republic of Tanzania OR Zambia OR Zimbabwe

An article was selected for inclusion in the study if it was a primary research paper reporting original research done in Africa and included at least one laboratory test result, with biological sample collected or processed in Africa. Biological samples included blood (including dried blood spots), urine, stool, biopsies and swabs (throat, anal, vaginal, and so on). Studies that evaluated behaviours, archival specimens and isolates in addition to studies based on plant, water, environmental and animal samples were excluded. Review papers, editorials and opinion papers that did not contain primary data were also not eligible for this study. Concerning authorship, only first and last authorship were examined. Corresponding authors were excluded as they are not always first or last authors. Given that further information to guide assignment of institution is not practically available for a review of this nature. The country of affiliation for the author was assigned based on listed institution on the paper. When authors had multiple affiliations that included an African country, they were assigned to the African affiliation for the purpose of the study.

Based on reading of the abstracts, articles were confirmed to be either a clinical trial or an epidemiological study and then doubly assessed by two reviewers against the inclusion and exclusion criteria. A third reviewer with expertise on the relevant diseases reevaluated the list of included and excluded studies based on the eligibility criteria to make a final decision on the list of articles included for analysis. From the final included list of studies, data related to authorship, country of affiliation, reception of funding and language spoken by authors (based on country of affiliation) were compiled in a study database. Data were cleaned to standardise the terms used for analysis and reporting. We used R Studio (V.1.0.153) data analysis software to estimate proportions, CI and hypothesis testing, as well as generate descriptive plots. We also used R Studio to compare the proportion of African first and/or last authors to non-African per study type, disease, country and language. The tests were two-tailed. Any difference was considered significant if the p-value was $<0.05$.

\section{Patients and public involvement}

No patients were involved on this study.

\section{RESULTS}

\section{Articles included in the analysis}

We retrieved 2871 articles that included both clinical trials and epidemiological studies on HIV, malaria, tuberculosis, salmonellosis, Ebola and Buruli conducted in Africa. Of these, 1182 articles met the inclusion criteria for the study (figure 1). Overall, we had a $41.2 \%$ inclusion rate with disease-specific rates being: malaria: 325/554 (58.7\%), tuberculosis: 230/561 (41.0\%), HIV: 386/1123 (34.4\%), Ebola: 77/332 (23.2\%), salmonellosis: 134/254 (52.8\%) and Buruli: 30/47 (63.8\%) (figure 1). Regarding study type, 502 out of $1182(42.5 \%)$ of articles included were clinical trials, while the remaining $680(57.5 \%)$ represent epidemiological studies. Most of the reviewed articles were on HIV $(n=386)$, malaria $(n=325)$ and tuberculosis $(\mathrm{n}=230)$, with salmonellosis $(\mathrm{n}=134)$, Ebola $(\mathrm{n}=77)$ and Buruli $(\mathrm{n}=30)$ expectedly yielding fewer papers (figure 2). The proportion of studies with laboratory tests performed in Africa ranged from $68 \%$ to $90 \%$ across the six diseases under study.

\section{African authorship}

Of the 1182 articles included, $1109(93.2 \%)$ had at least one author affiliated to an African institution (AI). Approximately half $(n=552,49.8 \%)$ of all the articles reviewed had a first author affiliated to an AI, while $41.3 \%(n=458)$ had a last author affiliated to an AI.

\section{Number of African countries involved in research done in Africa and African authorship per disease}

Table 1 lists the general characteristics of the articles included in this analysis. Researchers from more African countries published on malaria research than any of the other diseases, ${ }^{19}$ followed by salmonellosis ${ }^{20}$ and HIV. ${ }^{21}$ Across most of the diseases studied, well under half of the articles had Africans as first or last authors (table 1). For Ebola, only $25 \%$ of authors in these lead positions were Africans. Salmonellosis had a higher proportion of lead African authors (0.7, CI 0.62 to 0.78 ) compared with other five diseases, and more than double of the other two moderately researched diseases (ie, Ebola and Buruli). The proportion of African last authors for HIV (0.36, CI 0.31 to 0.41$)$ and malaria (0.37, CI 0.31 to 


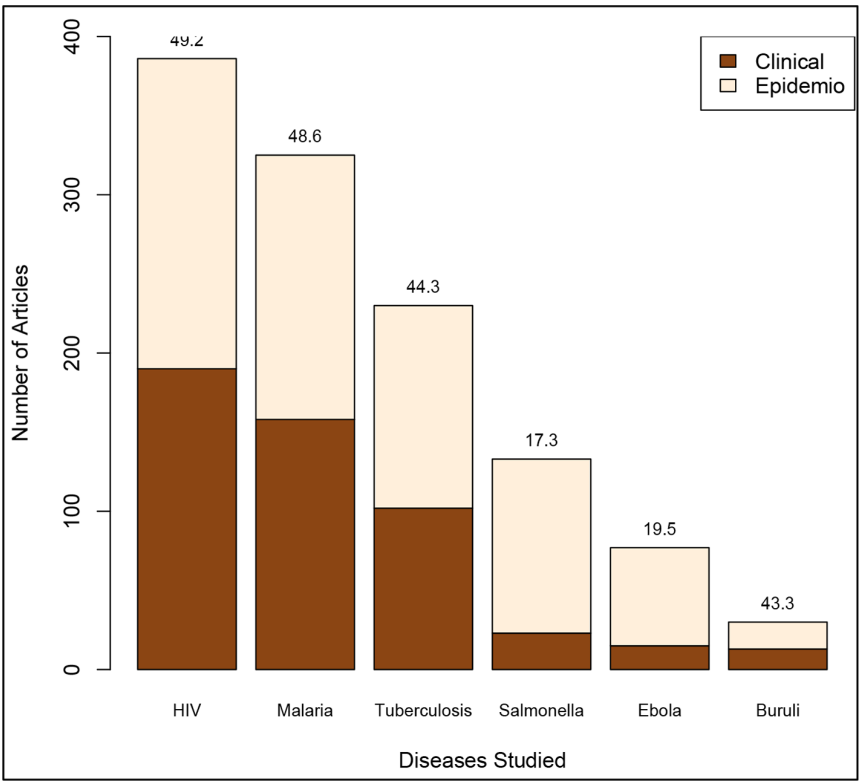

Figure 2 Number of articles included in the study by disease, in the order of publication volume, and reflecting study types (clinical trials and epidemiological studies). The numbers on top of each bar represent the percentage of clinical trials from all studies included per disease.

$0.42)$ is significantly lower than the proportion of African first authors in those two diseases, respectively $(0.51$, CI 0.46 to 0.56 ) and ( 0.55 , CI 0.49 to 0.60$)$. The opposite is observed in tuberculosis with the proportion of African last authors $(0.53$, CI 0.46 to 0.59$)$ being higher in this case than the proportion of African first authors (0.37, CI 0.31 to 0.44$)$.

\section{Funding source}

In terms of extramural funding (table 1), salmonellosis was the disease with the lowest proportion of studies acknowledging financial support (0.48, CI 0.39 to 0.57$)$. HIV, malaria, tuberculosis and Ebola had high percentages of studies that reported receiving funding (greater than $70 \%$ ), but under $10 \%$ of the acknowledged funding was from African country sources. As suggested by the coinciding CIs, whether or not the first or last authors are affiliated to AI does not seem to affect the reception of funding.

\section{Proportions of first and last African vs non-African authors based on authors' countries of affiliation}

As demonstrated in figure 3, salmonellosis research has the highest proportion of African last authors ( 7 out of 10 ), followed by HIV and malaria (5 out of 10 each), Ebola (4 out of 10), tuberculosis (3 out of 10) and Buruli (2 out of 10$)$. With the exception of salmonellosis and tuberculosis, all other diseases have a statistically significant higher proportion of last authors from non-AIs $(\mathrm{p}<0.001)$. Both highly researched and moderately researched diseases have a higher proportion of non-African last authors (ie, $64.0 \%$ and $59.7 \%$; $\leq \leq 0.001$ ). The non-African countries that dominated last authorship positions in African endemic disease research are the USA, the UK, France, Belgium and Germany (figure 4). China's involvement is mostly focused on Ebola, while countries like the USA, the UK, France and Belgium are represented across all diseases. African countries with the greatest representation of last authorships are South-Africa, Ethiopia, Nigeria, Kenya and Ghana (figure 4). As with first authorships, there was some skew seen towards endemic countries for malaria and Buruli ulcer diseases.

\section{Authorship versus study types and lingua franca}

In figure 5, the inner circle shows the proportion of the reviewed articles focusing on the six diseases, the middle circle shows the proportion of the articles describing research from an epidemiological or a clinical perspective for each disease. The outer circle shows the origin of the author separated by 'African' origin versus 'Non-African' origin per study type and disease.

As shown in figure $5 \mathrm{~A}$, out of the six diseases, only Ebola and tuberculosis have a significantly lower proportion of African first authors in clinical trials papers than non-African first authors with $p$-values $<0.001$ for both diseases. Salmonellosis, on the other hand, while having many fewer clinical trials overall, has a significantly higher proportion of African first authorships in clinical trials $(p=0.025)$. Tuberculosis and HIV, highly researched diseases of international significance, have a significantly lower proportion of African first authors $(\mathrm{p}<0.001$ and $\mathrm{p}=0.019$, respectively). As figure $5 \mathrm{~B}$ displays, aside from salmonellosis and tuberculosis, all other four diseases have a significantly higher proportion of non-African last authors as compared with African authors in clinical trials studies $(p=0.027)$. Additionally, the proportion of African last authors in clinical trials is lower than that of African last authors in epidemiological studies (30.2 vs $46.1 \% \mathrm{p}=0.027)$.

We assessed the representation of lingua franca of the countries to which first and last authors from AIs are affiliated (figure 6). The inner circle shows the proportion of the reviewed articles focusing on the six diseases, the second circle shows the origin of the author separated by 'African' origin versus 'Non-African' origin for each disease, the third circle shows the proportion of 'one of the official languages' of the countries of the author's origin for the authors with African origin and the outer circle shows the proportion of the country where most of the articles were published versus all other countries among the most common official language of the author's country of origin.

For all six diseases considered, first (figure 6A) and last authors (figure 6B) are predominately drawn from Anglophone countries, with differences in proportions giving statistically significant $\mathrm{p}<0.001$. This is true for both first and last authors for HIV, tuberculosis and salmonellosis, and for first authors only for malaria and Buruli, the two endemic diseases with endemic foci in only some countries. Francophone countries are more likely to have lead authorships for those two diseases as compared with other diseases, while authors affiliated to Arabic-speaking 
Table 1 Summary and comparison of the study outcomes for all six diseases

\begin{tabular}{|c|c|c|c|c|c|c|}
\hline & HIV & Malaria & Tuberculosis & Salmonellosis & Ebola & Buruli \\
\hline $\begin{array}{l}\text { Period of } \\
\text { Publication } \\
\text { Evaluated }\end{array}$ & $\begin{array}{l}\text { August } 1,2014 \text { to } \\
\text { July } 31,2016\end{array}$ & $\begin{array}{l}\text { August } 1,2014 \text { to } \\
\text { July } 31,2016\end{array}$ & $\begin{array}{l}\text { August } 1,2013 \text { to } \\
\text { July } 31,2016\end{array}$ & $\begin{array}{l}\text { August } 1,1980 \text { to } \\
\text { July } 31,2016\end{array}$ & $\begin{array}{l}\text { August } 1,1980 \text { to } \\
\text { July } 31,2016\end{array}$ & $\begin{array}{l}\text { August } 1,1980 \text { to } \\
\text { July } 31,2016\end{array}$ \\
\hline $\begin{array}{l}\text { Number of articles } \\
\text { included after final } \\
\text { review }\end{array}$ & 386 & 325 & 230 & 134 & 77 & 30 \\
\hline $\begin{array}{l}\text { Proportion } \\
\text { of studies } \\
\text { with African } \\
\text { Researchers }\end{array}$ & $0.48(0.46-0.49)$ & $0.55(0.54-0.57)$ & $0.56(0.54-0.58)$ & $0.64(0.61-0.67)$ & $0.25(0.23-0.27)$ & $0.45(0.39-0.51)$ \\
\hline $\begin{array}{l}\text { Proportion of } \\
\text { studies with last } \\
\text { authors from } \\
\text { African Institutions }\end{array}$ & $0.36(0.31-0.41)$ & $0.37(0.31-0.42)$ & $0.53(0.46-0.59)$ & $0.64(0.55-0.72)$ & $0.23(0.15-0.35)$ & $0.17(0.06-0.35)$ \\
\hline $\begin{array}{l}\text { Proportion of } \\
\text { studies that } \\
\text { acknowledged any } \\
\text { funding source(s) }\end{array}$ & $0.8(0.76-0.84)$ & $0.88(0.84-0.91)$ & $0.71(0.65-0.77)$ & $0.48(0.39-0.57)$ & $0.64(0.52-0.74)$ & $0.87(0.68-0.96)$ \\
\hline $\begin{array}{l}\text { Proportion of } \\
\text { studies that } \\
\text { acknowledged } \\
\text { funding from } \\
\text { African Institutions }\end{array}$ & $0.05(0.03-0.08)$ & $0.08(0.06-0.12)$ & $0.09(0.06-0.13)$ & $0.01(0-0.06)$ & $0.13(0.07-0.23)$ & $0.07(0.01-0.24)$ \\
\hline $\begin{array}{l}\text { Proportion of } \\
\text { studies that } \\
\text { acknowledged } \\
\text { funding when last } \\
\text { author is from } \\
\text { African Institutions }\end{array}$ & $0.74(0.66-0.81)$ & $0.79(0.7-0.86)$ & $0.65(0.56-0.74)$ & $0.45(0.35-0.56)$ & $0.39(0.18-0.64)$ & $0.6(0.17-0.93)$ \\
\hline $\begin{array}{l}\text { Proportion of } \\
\text { studies with } \\
\text { laboratory tests } \\
\text { done in Africa }\end{array}$ & $0.74(0.7-0.79)$ & $0.79(0.74-0.84)$ & $0.9(0.85-0.93)$ & $0.68(0.59-0.76)$ & $0.78(0.67-0.86)$ & $0.83(0.65-0.94)$ \\
\hline
\end{tabular}

The total number of articles for each disease is analysed by number of articles, place of research and lab test, first and last authorship, and funding availability.

The general characteristics of the articles included in the analysis based on the six diseases with the mean of the sample estimate and confidence interval at a 95\% confidence level represented in brackets.

Aln, African Institutions; AR, African Researchers.

countries are more involved in salmonellosis research than other diseases. For practically all the diseases, lingua franca data are skewed towards specific countries such as South Africa and Kenya for Anglophone countries regarding HIV and tuberculosis, while Burkina Faso and Cameroon skew data for Francophone countries in malaria.

\section{DISCUSSION}

This study assessed authorship in publications reporting scientific findings from the highly researched malaria, HIV and tuberculosis, as well as from moderately researched diseases salmonellosis, Ebola haemorrhragic fever and Buruli ulcer. Overall, of the articles included, 
A

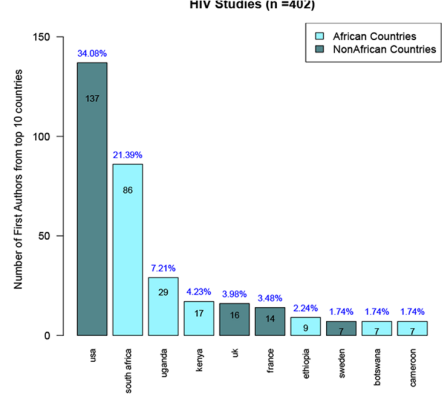

B

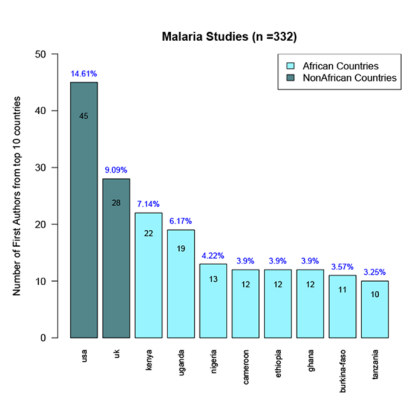

A

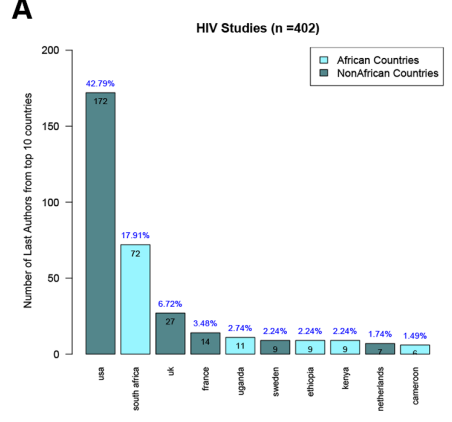

C

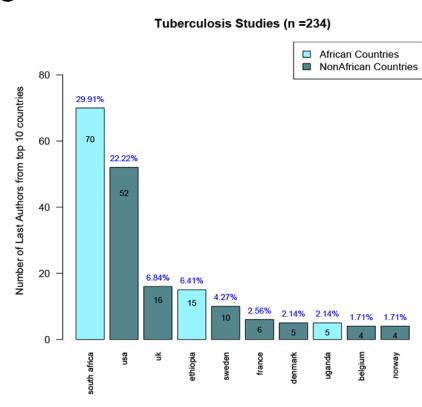

B

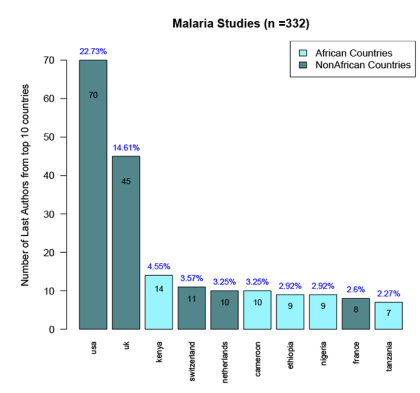

D

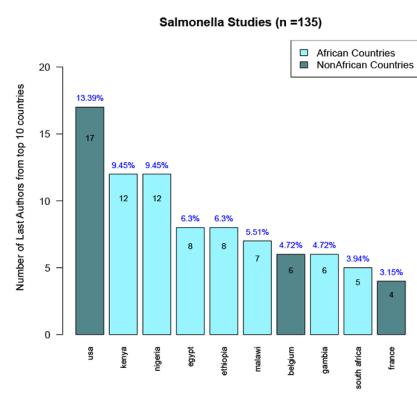

C

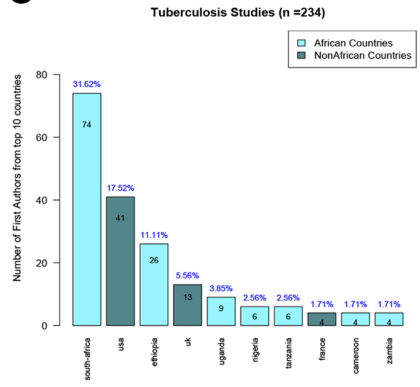

E

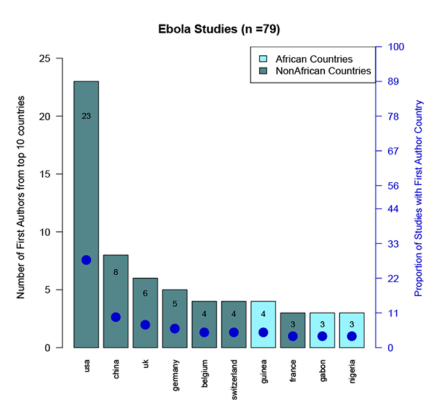

D

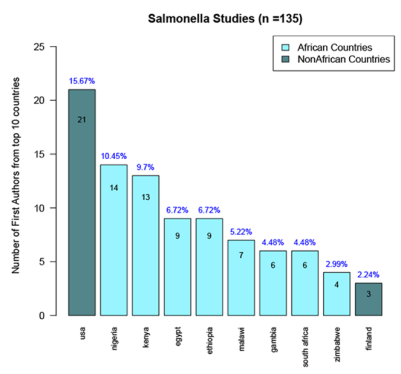

$\mathbf{F}$

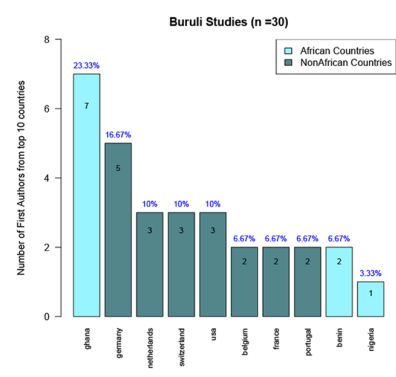

Figure 3 Number and proportion of first authors by country for each of the six diseases: (A) HIV (B) malaria (C) tuberculosis (D) salmonellosis (E) Ebola, and (F) Buruli. Each graph displays the top 10 countries represented by the first authors of the articles included for each disease in terms of frequency (on the left axis) denoted by the bars and proportions of first authors (on the right axis).

only 93.2\% had any African authors represented. While this number is high, it points to almost $8 \%$ of articles from Africa using Africa-collected specimens that lack a co-investigator that meets the International Committee of Medical Journal Editors authorship criteria. ${ }^{22}$ Of those that did include an African author, only $49.8 \%$ had an African first author and $41.3 \%$ had an African last author. There is a geographical inequity in the representation of African first and last authors involved in highly and moderately researched infectious disease research. Anglophone countries like South-Africa, Ethiopia, Nigeria, Kenya and Ghana are the most represented countries of origin of African first and last authors. 

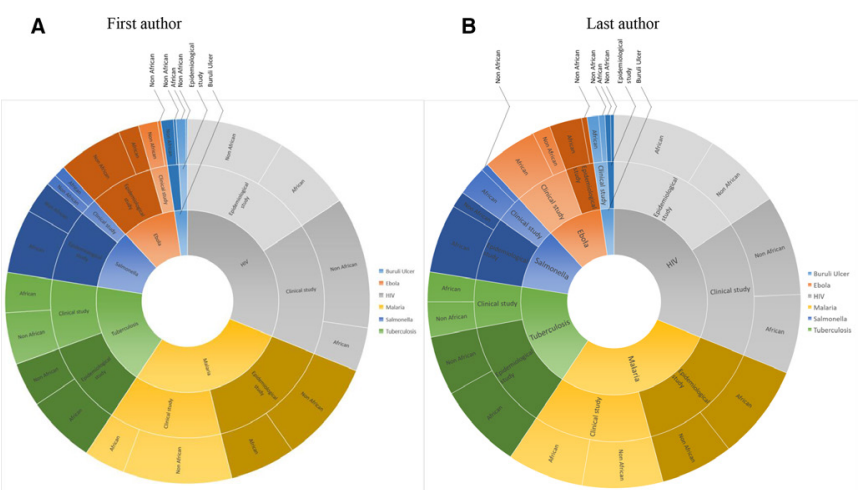

Figure 5 First and last authors per each of the six diseases and by study types (epidemiological or clinical).

Each sunburst displays the repartition of first and last African vs Non-African researchers per type of study (clinical vs epidemiological) for each disease.

collaborations. ${ }^{23}$ These collaborations are mostly with non-African partners and could involve unequal partnerships. Our own research shows that only a minority of articles have Africans as first and last authors.

A number of studies report similar findings. Lyer analysed authorship trends in the Lancet Global Health and found that the majority of studies published are conducted in Africa (40\%) with scanty LMIC authorship contribution (44\%) for articles from Africa. However, this study did not break down the analysis and it was restricted to the Lancet Global Health Journal only. The analysis was performed by a single author therefore could have been erroneous. ${ }^{24}$ Similarly, Rees and collaborators found a trivial authorship contribution from LMICs $(15.5 \%)$ and LICs $(5.4 \%)$ authors to paediatric research conducted in LMICS. ${ }^{25}$ There is evidence that lead authorship has increased in LMICs but this is not significant. Chersich et al mapped authorship of maternal health interventional research in LMICs and they found that only $25 \%$ of LMIC lead the majority of their research $(75 \%)$. In summary, approximately half of authors with
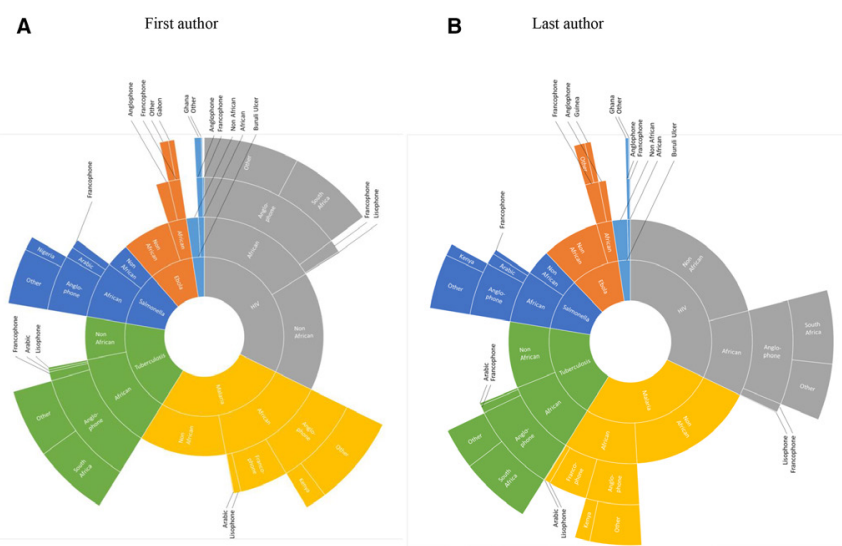

Figure 6 First and last authors per each of the six diseases and by languages (Anglophone, Francophone and Arabic). Each sunburst displays the repartition of first and last African vs Non-African researchers for each disease per language and including the most represented African country.
LMICs affiliation lead research conducted in their countries. When analysed by study type, authorship lead was drastically low for systematic reviews (26.8\%), modelling studies $(29.9 \%)$ and for articles published in journals with a high impact factor $(>5)(33.2 \%) .{ }^{26}$ Again, there was no comprehensive description of authorship by country nor lingua franca as provided in the current study. Several other studies report discrepancies in data proprietorship for studies conducted in the LMICs. ${ }^{21} 2728$

Ebola and Buruli ulcer are solely or largely found in some zones of Africa, respectively. It has been observed that African authors working on Buruli ulcer are more likely to work towards health-related outcomes. ${ }^{29}$ The fact that 7 out of the 10 top countries of first authors conducting studies on Ebola and Buruli in Africa are non-African points to a dearth of African leadership in these areas that may in fact connect to the slow rate of outcomes. We note that ethnography on neglected diseases and their neglected actors recorded the testimony of local professionals, who have long experience with Buruli ulcer frustrated of being, in the best cases, merely 'acknowledged' in a footnote to the final publications. ${ }^{30}$

For most highly researched diseases, the story is not much different. The proportion of African last authors is also particularly lower than the proportion of African first authors for HIV and malaria. In fact, with the exception of salmonellosis, five of the six diseases have a higher proportion of non-African last authors, with senior authorships predominantly from the USA, the UK, France, Belgium and Germany. Within Africa, research leadership as computed from first and last authorships mostly comes from only six countries: South Africa, Ethiopia, Nigeria, Kenya and Ghana. If we take out these star researcher countries, which themselves mostly include only a handful of star researchers, very little research leadership is evidenced across the continent.

Our study revealed that African Anglophone countries dominate as first and last authors of papers for all six diseases studied. This finding could be as a result of international scientific collaboration which in many cases is conducted in English. ${ }^{23}$ Additionally, tropical medicine, as a research discipline, has roots in colonial Britain and was critical to the attainment of the colonial British agenda. ${ }^{203132}$ While there are no more British colonies in Africa, decolonisation does not appear to have brought local ownership or credit for biomedical research on African disease even though it may explain some of the ascendancy of Anglophone countries when it comes to infectious disease research. This, notwithstanding, France, Belgium and Germany are also important contributors to Africa endemic area research. We also found out that francophone countries are more involved in malaria research. This could be pertaining to three primary reasons: first, West Africa, which is predominately francophone, is disproportionally affected by malaria, and accounts for half of the global burden. ${ }^{33}$ Second, the shared factor among West African countries 
is almost certainly their common use of French, which makes scientific collaboration to be driven strongly by language ${ }^{34}$ Finally, the Institute Pasteur Network laboratories in Africa, predominantly located in Western and Central Africa, have a strong focus in malaria. ${ }^{19}$ This third critical factor again points to colonial heritage and links as the chief factor underpinning research leadership across the continent. Similar collaborative patterns, but at lower levels were seen for Buruli ulcer, which has endemic foci in Cameroon and Benin. Nigeria may act as a bridge between Anglophone and Francophone areas, making its international collaboration rate higher. ${ }^{7}$

Although previous studies have also analysed research output trends in authorship proportions and comparisons, ${ }^{21}{ }^{24-28}$ this is the first report, to our knowledge, that provides comprehensive analysis of first and last authorship assessments between African and non-African groups as well as assessment of high profile versus endemic diseases. However, our study is not without limitations. For instance, one limitation of the study was that most of the analysis was done manually; however, this was counterbalanced by having at least three authors assess each paper. Manual analysis made it impossible to determine temporal authorship patterns for more than three diseases. Additionally, for highly researched diseases, our search was necessarily limited to the period between 2014 and 2016 and could not be compared over the same time frame (1980 to 2016) due to the large number of publications available for infectious diseases like HIV, malaria and tuberculosis. As such, there was a limited consistency in the search strategy. Another limitation was our exclusion of 'corresponding authors' - who are lead authors that are often but not always first or last authors. ${ }^{35}$ Moreover, it was challenging to find out the nationality of the author as we wanted to represent the country of affiliation in our results. Using institutional affiliation as a proxy for nationality or country of origin will have led to misclassifications. For example, an African researcher working on malaria but based in an institution in the UK would be included in the non-African group. Thus, our study discounts Africa's large scientific diaspora, classifying them as non-Africans unless they declared an African affiliation. Similarly, a non-African researcher with an African affiliation would have been classified as African for the purpose of our study. Altogether, our methodology will have produced an over-reporting of African scientists and would therefore overestimate the relatively low rates of African authorship recorded. Finally, by using only PubMed as the sole database for our article sources, our assessment of lingua franca might also have been biased towards English.

Collaboration can benefit all sides and serve common interests by producing excellent research which can help expand scientific knowledge as well as communicate the work through joint publications. While such collaboration and the necessary divisions of tasks are constructive, there may be grey areas in responsibility sharing and/ or less than fair ${ }^{11}$ representation in published journals.
Thus, it is important to realise that while Westerners may bring funding and/or technical expertise, the necessary context those local researchers should bring, among other contributions, may be lacking. This has overall consequences for the quality of the research and the benefits it can bring. Lopsidedness in funding is often blamed for research participation inequities. Increased interest and investment in African-led research by funding and scientific institutions from the USA and Europe, and the recent establishment of a continental funding presence in the form of the Alliance for Accelerating Excellence in Science in Africa (AESA) are all aimed at creating strong academic partnerships and to leveraging the development of technological solutions to Africa-endemic diseases. Our evaluation periods ended in 2016 and it remains to be seen whether a future study of this nature performed after these initiatives are well established will detect significant improvements in research equity and African leadership in publications.

Funding is however not the only factor driving leadership. African scientists and academic societies need to engender more visibility for local and locally led research by publishing it in the indexed literature. There also needs to be a greater local investment in ethical and regulatory policies to support career development and insist on equity as well as to build the articulation skills needed for proposal and paper writing and research leadership. AIs also must be mindful of the issue at hand and must avail African researchers protected time and support to meaningfully be involved in research and not just named co-investigators on grants and studies. African researchers should be involved in the conduct of research from conception to dissemination of results, thereby making significant inputs. Research funding institutions could help by insisting on shared authorship or an explanation when this is not possible, when they fund partnerships.

Science and technology study investigators that have evaluated partnerships have often found that AIs provide field sites, patients, samples and data, while Western partners provide funds and technical expertise (especially for data analysis, interpretation and writing). ${ }^{36} 37$ Many of these reports are based on empiric data although of limited in scope and location. ${ }^{29}$ Our findings in this study were that for all the diseases studied, most of the biological testing takes place on the continent but much of the credit for publication leadership is elsewhere. Therefore, while the full contribution of Africans to science is yet to be quantified, local scientific activity is taking place.

\section{CONCLUSION}

The results of our study showed that African researchers are under-represented in the most important positions (ie, first and last authorship positions) on papers from research performed in Africa. Within Africa, certain geographical areas, particularly non-Anglophone ones are further under-represented. We also found that the 
representation varies per diseases and also study types. To address this challenge, there is an opportunity to build more research capacity using African funds while implementing more equitable partnership to ensure African researchers are telling their story.

\section{Author affiliations}

'Department of Epidemiology, University of Rochester, Rochester, New York, USA

${ }^{2}$ Department of Public Health, Stanford University, Stanford, California, USA

${ }^{3}$ CTU Bern, University of Bern, Bern, Switzerland

${ }^{4}$ Department of Public Health, Universite Catholique de l'Afrique Centrale, Yaounde, Cameroon

${ }^{5}$ Cameroon Mission, Medecins Sans Frontieres, Geneva, Switzerland

${ }^{6}$ Department of Public Health, University of Buea, Buea, Cameroon

${ }^{7}$ Epicentre, Yaounde, Centre, Cameroon

${ }^{8}$ Department of Pharmacology, University of Ghana, Legon, Ghana

${ }^{9}$ Department of Microbiology, University of Ibadan, Ibadan, Nigeria

${ }^{10}$ Department of Public Health, University of California Berkeley, Berkeley, California, USA

${ }^{11}$ Independent Researcher, Paris, France

${ }^{12}$ Center for Global Health, Massachusetts General Hospital, Boston, Massachusetts, USA

${ }^{13}$ Department of Medicine, Harvard Medical School, Boston, Massachusetts, USA

${ }^{14}$ Department of Medicine, Massachusetts General Hospital, Boston,

Massachusetts, USA

${ }^{15}$ Department of Microbiology, Mbarara University of Science and Technology,

Mbarara, Uganda

Twitter Yap Boum @yap.boum2

Acknowledgements We acknowledge Juliet Mwanga-Amumpaire, Daniel Atwine Dan Nyehangane, Patrick Orikiriza, Titilayo Mabogunje, Rodrigue Ntone, Stanley Ewala, Patrick Zamba, Justin Eyong, Robert Nsaibirani and Grace Umerani for their support on this work.

Contributors YB and INO conceived the protocol; RM, RG, SH, NFM, EBN, LE, TOA, AO, GK and YB participated in the data collection; RM, RG, SH, MS and JH participated in the data analysis; RM, RG, SH, NFM, EBN, LE, TOA, AO, GK, YM, MS, INO, JH and YB participated in the article writing.

Funding The authors have not declared a specific grant for this research from any funding agency in the public, commercial or not-for-profit sectors.

Competing interests None declared.

Patient consent for publication Not required.

Provenance and peer review Not commissioned; externally peer reviewed.

Data availability statement Data are available in a public, open access repository. Data are available on reasonable request. Data may be obtained from a third party and are not publicly available. All data relevant to the study are included in the article or uploaded as supplementary information.

Open access This is an open access article distributed in accordance with the Creative Commons Attribution Non Commercial (CC BY-NC 4.0) license, which permits others to distribute, remix, adapt, build upon this work non-commercially, and license their derivative works on different terms, provided the original work is properly cited, appropriate credit is given, any changes made indicated, and the use is non-commercial. See: http://creativecommons.org/licenses/by-nc/4.0/.

ORCID iD

Yap Boum http://orcid.org/0000-0002-6823-8539

\section{REFERENCES}

1 Wemos. Clinical trials in Africa: the cases of Egypt, Kenya, Zimbabwe and South Africa. Issuu, 2018. Available: https://issuu. com/stichtingwemos2017/docs/jh_wemos_clinical_trials_v5_def [Accessed 12 Sep 2018].

2 Einarsdottir T, Huygen K. Buruli ulcer. Hum Vaccin 2011;7:1198-203.

3 Bliziotis IA, Paraschakis K, Vergidis PI, et al. Worldwide trends in quantity and quality of published articles in the field of infectious diseases. BMC Infect Dis 2005;5:16.
4 Mohamedbhai G. Promoting developmental research: a challenge for African universities. JL4D 2014;1.

5 Uthman OA, Uthman MB. Geography of Africa biomedical publications: an analysis of 1996-2005 PubMed papers. Int J Health Geogr 2007;6:46

6 Tijssen RJW. Africa's contribution to the worldwide research literature: New analytical perspectives, trends, and performance indicators. Scientometrics 2007;71:303-27.

7 Mêgnigbêto E. International collaboration in scientific publishing: the case of West Africa (2001-2010). Scientometrics 2013;96:761-83.

8 Ettarh R. Patterns of international collaboration in cardiovascular research in sub-Saharan Africa. Cardiovasc J Afr 2016;27:194-200.

9 John CC, Ayodo G, Musoke P. Successful global health research partnerships: what makes them work? Am J Trop Med Hyg 2016;94:5-7.

10 Hess C, Brückner C, Kaiser T, et al. Authorship in scientific publications: analysis and recommendations. Swiss Medical Weekly 2015.

11 Bhattacharya S, explained Aissue. Authorship issue explained. Indian J Plast Surg 2010;43:233-101.

12 Hundley V, Teijlingen E, Simkhada P, et al. Academic authorship: who, why and in what order? Health Renaissance 2013;11:99-101.

13 Chu KM, Jayaraman S, Kyamanywa P, et al. Building research capacity in Africa: equity and global health collaborations. PLoS Med 2014;11:e1001612.

14 Home - PubMed - NCBI, 2018. Available: https://www.ncbi.nlm.nih. gov/pubmed [Accessed 12 Sep 2018].

15 Moher D, Liberati A, Tetzlaff J, et al. Preferred reporting items for systematic reviews and meta-analyses: the PRISMA statement. PLoS Med 2009;6:e1000097.

16 MacNeil A, Rollin PE. Ebola and Marburg hemorrhagic fevers: neglected tropical diseases? PLoS Negl Trop Dis 2012;6:e1546.

17 Rabsch W, Tschäpe H, Bäumler AJ. Non-typhoidal salmonellosis: emerging problems. Microbes Infect 2001;3:237-47.

18 Murray CJL, Ortblad KF, Guinovart C, et al. Global, regional, and national incidence and mortality for HIV, tuberculosis, and malaria during 1990-2013: a systematic analysis for the global burden of disease study 2013. The Lancet 2014;384:1005-70.

19 Marie-Helene M, Francois G. The story of the Pasteur Institute and its contributions to global health. Cambridge Scholars Publishing, 2018.

20 Geissler W, Lachenal G, Manton J. Traces of the future: an archaeology of medical science in Africa. Intellect Ltd Bristol 2016.

21 Pastrana T, Vallath N, Mastrojohn J, et al. Disparities in the contribution of low- and middle-income countries to palliative care research. J Pain Symptom Manage 2010;39:54-68. 1.

22 International Committee of Medical Journal Editors (ICMJE). Uniform requirements for manuscripts submitted to biomedical journals: writing and editing for biomedical publication. J Pharmacol Pharmacother 2010;1:42-58.

23 World Bank and Elsevier. A decade of development in sub-Saharan African science, technology, engineering and mathematics research (English), 2014. Available: http://documents.worldbank.org/curated/ en/237371468204551128/A-decade-of-development-in-subSaharan-African-science-technology-engineering-and-mathematicsresearch

24 Iyer AR. Authorship trends in the Lancet global health. Lancet Glob Health 2018;6:e142.

25 Rees CA, Lukolyo H, Keating EM, et al. Authorship in paediatric research conducted in low- and middle-income countries: parity or parasitism? Trop Med Int Health 2017;22:1362-70.

26 Chersich MF, Blaauw D, Dumbaugh M, et al. Local and foreign authorship of maternal health interventional research in low- and middle-income countries: systematic mapping of publications 2000-2012. Global Health 2016;12:35.

27 Jacobsen $\mathrm{KH}$. Patterns of co-authorship in international epidemiology. J Epidemiol Community Health 2009;63:665-9.

28 Aluede EE, Phillips J, Bleyer J, et al. Representation of developing countries in orthopaedic journals: a survey of four influential orthopaedic journals. Clin Orthop Relat Res 2012;470:2313-8.

29 Okeke IN. African biomedical scientists and the promises of "big science". Can J Afr Stud/ Revue canadienne des études africaines 2016:50:455-78

30 Lachenal G, Owona Ntsama J, Ze Bekolo D, et al. Neglected actors in neglected tropical diseases research: historical perspectives on health workers and contemporary Buruli ulcer research in Ayos, Cameroon. PLoS Negl Trop Dis 2016;10:e0004488.

31 Banerjee A. The British Raj and rise and fall of tropical medicine. Med J DY Patil Univ 2013:6:121-2. 
32 Tilley $\mathrm{H}$. Africa as a living laboratory: Empire, development, and the problem of scientific knowledge, 1870-1950. The University of Chicago 2011.

33 Regional Impact Francophone Countries. The global fund, 2016. Available: https://www.theglobalfund.org/media/1616/ publication_regionalimpactfrancophonecountries_report_en.pdf?u= 636609570670000000
34 Adams J, Gurney K, Hook D, et al. International collaboration clusters in Africa. Scientometrics 2014;98:547-56.

35 Weiss PS. Who are corresponding authors? ACS Nano 2012;6:2861.

36 Boum IIY. Is Africa part of the partnership? Medicine Anthropology Theory 2018:27-34.

37 Moyi Okwaro F, Geissler PW. In/dependent collaborations: perceptions and experiences of African scientists in transnational HIV research. Med Anthropol Q 2015;29:492-511. 